\title{
A ten year review of the sickle cell program in Muhimbili National Hospital, Tanzania
}

\author{
Julie Makani ${ }^{1,2,3^{*}}$ (D), Furahini Tluway ${ }^{1}$, Abel Makubi ${ }^{1}$, Deogratius Soka ${ }^{1}$, Siana Nkya ${ }^{1,4}$, Raphael Sangeda ${ }^{1}$, \\ Josephine Mgaya ${ }^{1}$, Stella Rwezaula 1,3, Fenella J. Kirkham5, Christina Kindole ${ }^{1,3}$, Elisha Osati, ${ }^{1,3}$, Elineema Meda ${ }^{3}$, \\ Robert W. Snow ${ }^{2,6}$, Charles R. Newton ${ }^{2,6}$, David Roberts ${ }^{2}$, Muhsin Aboud', Swee Lay Thein ${ }^{7}$, Sharon E. Cox ${ }^{8}$, \\ Lucio Luzzatto ${ }^{1+}$ and Bruno P. Mmbando ${ }^{1,9 \dagger}$
}

\begin{abstract}
Background: Africa has the highest burden of Sickle cell disease (SCD) but there are few large, systematic studies providing reliable descriptions of the disease spectrum. Tanzania, with 11,000 SCD births annually, established the Muhimbili Sickle Cell program aiming to improve understanding of SCD in Africa. We report the profile of SCD seen in the first 10 years at Muhimbili National Hospital (MNH).

Methods: Individuals seen at MNH known or suspected to have SCD were enrolled at clinic and laboratory testing for SCD, haematological and biochemical analyses done. Ethnicity was self-reported. Clinical and laboratory features of SCD were documented. Comparison was made with non-SCD population as well as within 3 different age groups $(<5,5-17$ and $\geq 18$ years) within the SCD population.

Results: From 2004 to 2013, 6397 individuals, 3751 (58.6\%) SCD patients, were enrolled, the majority (47.4\%) in age group 5-17 years. There was variation in the geographical distribution of SCD. Individuals with SCD compared to non-SCD, had significantly lower blood pressure and peripheral oxygen saturation $\left(\mathrm{SpO}_{2}\right)$. SCD patients had higher prevalence of severe anemia, jaundice and desaturation $\left(\mathrm{SpO}_{2}<95 \%\right)$ as well as higher levels of reticulocytes, white blood cells, platelets and fetal hemoglobin. The main causes of hospitalization for SCD within a 12-month period preceding enrolment were pain (adults), and fever and severe anemia (children). When clinical and laboratory features were compared in SCD within 3 age groups, there was a progressive decrease in the prevalence of splenic enlargement and an increase in prevalence of jaundice. Furthermore, there were significant differences with monotonic trends across age groups in SpO2, hematological and biochemical parameters.

Conclusion: This report confirms that the wide spectrum of clinical expression of SCD observed elsewhere is also present in Tanzania, with non-uniform geographical distribution across the country. Age-specific analysis is consistent with different disease-patterns across the lifespan.
\end{abstract}

Keywords: Sickle cell anemia, Africa, Tanzania

\section{Background}

The highest burden of sickle cell disease (SCD) is in Africa where up to $75 \%$ of the 300,000 global births of SCD per year occur [1] and where childhood mortality remains high, ranging between 50 and $90 \%$ [2]. Much of what is known about the spectrum of SCD is from cohort studies

\footnotetext{
* Correspondence: jmakani@blood.ac.tz

+Lucio Luzzatto and Bruno P. Mmbando contributed equally to this work.

${ }^{1}$ Muhimbili University of Health and Allied Sciences, Dar-es-Salaam, Tanzania

2University of Oxford, Oxford, UK

Full list of author information is available at the end of the article
}

in USA [3], Europe and Jamaica [4-6], with few studies carried out in Africa [7-10] although it is recognized that there is a need for detailed prospective, epidemiological studies [11]. Tanzania is amongst the 5 countries in the world with the highest estimated number of newborns with SCD a year [12] (Nigeria 85,000, Democratic Republic of Congo 42,000, India 38,000; Tanzania 11,000 and Uganda 10,000 [1, 11]). The World Health Organization (WHO) has formally classified SCD as a major public health problem [13] and Tanzania, like other African countries has included SCD as a priority disease condition

(c) The Author(s). 2018 Open Access This article is distributed under the terms of the Creative Commons Attribution 4.0 International License (http://creativecommons.org/licenses/by/4.0/), which permits unrestricted use, distribution, and reproduction in any medium, provided you give appropriate credit to the original author(s) and the source, provide a link to the Creative Commons license, and indicate if changes were made. The Creative Commons Public Domain Dedication waiver (http://creativecommons.org/publicdomain/zero/1.0/) applies to the data made available in this article, unless otherwise stated. 
in their strategy for Non-Communicable Diseases (NCD) $[13,14]$. In 2004, Tanzania established the Muhimbili Sickle cell (MSC) program [15], integrating research and healthcare in a countrywide referral hospital for all disease conditions, the Muhimbili National Hospital (MNH). The main goal was to conduct research that would delineate the spectrum of disease, identify the main causes of morbidity and mortality and provide evidence-based knowledge that would improve healthcare through the introduction of locally-appropriate interventions and policies. Preliminary information on this population, particularly mortality rates [16], rates and risk factors for malaria [17, 18], bacterial infections [19] and other important clinical features [20-23] has been published. The MSC program has also provided a platform to conduct studies to describe genetic determinants of clinical disease [24], successfully conducting one of the first genome-wide association studies in SCD in Africa [25].

In this paper, we outline the profile of the cohort in the MSC program enrolled over the first 10 years. We then describe the clinical and laboratory features of the SCD population enrolled, as well as the geographical distribution, based on self-reported ethnicity. This program demonstrates the feasibility of conducting longitudinal, cohort studies in Africa and this baseline report is setting the stage for further detailed description of the course and spectrum of disease over time.

\section{Methods}

\section{Study site}

Tanzania has a population of 45 million and is classified as a low income country. The MSC program was established through collaboration between Muhimbili University of Health and Allied Sciences (MUHAS), the oldest and largest biomedical university in Tanzania and $\mathrm{MNH}$, the national referral hospital which is in Dar-es-Salaam on the Eastern coast.

\section{Study population}

Individuals attending $\mathrm{MNH}$ who were known or suspected clinically to have SCD or related to SCD individuals were invited to the clinic for enrolment.

\section{Clinic procedures}

The hospital had two clinics a week for SCD patients. During the course of the program, a third clinic was started. Patients were encouraged to visit the clinic in the event of an acute illness. All individuals who were enrolled were given a unique identifier number and hospital case number. Case report forms (CRF) were completed including demographic, clinical history and physical examinations. Residence information, including telephone number and consent to contact the family in case the patients did not attend clinic for more than
9 months were obtained. Management of SCD followed hospital guidelines which included prescription of folic acid $5 \mathrm{mg} /$ day, investigations to identify underlying additional causes of anaemia, blood transfusion (BT) for those with haemoglobin $<5 \mathrm{~g} / \mathrm{dL}$, or heart failure. Individuals with splenomegaly requiring $\mathrm{BT}$ ( $>3$ times a year) were referred for splenectomy. Oral iron was prescribed to those with iron deficiency, defined by low serum ferritin or empirically to those with low MCV $(<80 \mathrm{fl})$ and $\mathrm{MCHC}(<25 \mathrm{~g} / \mathrm{dL})$. Use of insecticide treated nets was emphasized to prevent malaria infections and chloroquine prophylaxis was prescribed until its use was discontinued due to high resistance. From 2010, SCD children under 5 years of age were prescribed daily oral penicillin.

\section{Laboratory procedures}

At enrolment visits, peripheral blood samples in EDTA were analyzed for full blood count (haemoglobin $(\mathrm{Hb})$, red blood cell count (RBC), mean corpuscular volume (MCV), mean corpuscular haemoglobin $(\mathrm{MCH})$, mean corpuscular haemoglobin Concentration (MCHC)], white blood cell (WBC) and platelet count (PLT) (Pentra 60, Horiba ABX, Kyoto, Japan; Sysmex XT2000i, Hyogo, Japan). Nucleated RBC could not be differentiated from neutrophils by the haematology analyzer. Reticulocyte count (New methylene blue method; Sysmex XT2000i, Hyogo, Japan) and fetal haemoglobin (HbF) levels by High performance Liquid Chromatography (HPLC) (BioRad, Hercules, CA, USA) were obtained. SCD diagnosis was made by HPLC and Haemoglobin electrophoresis (Helena, Sunderland, Tyne \& Wear, UK). Bilirubin total (BIL-T), bilirubin direct (BIL-D)], lactate dehydrogenase (LDH), alkaline phosphatase (ALP) and creatinine were assayed using a chemistry analyzer (Roche Cobas Mira, New York, USA or Abbott Architect, New York, USA). Daytime peripheral oxygen saturation $\left(\mathrm{SpO}_{2}\right)$ was determined using a pulse oximeter (pulse oximetry; Nellcor, Pleasanton, CA, USA). Peripheral Oxygen desaturation was defined as $<95 \%$.

\section{Data management and analysis}

Data were managed using MySQL database (Sun Microsystems Inc., Santa Clara, California, USA). Analysis was performed using STATA and R statistical software (http://www.R-project.org/). Continuous variables with normal distribution were compared using t-test or ANOVA test and skewed continuous variables were compared using Wilcoxon sign rank or Kruskal Wallis tests, while categorical data were compared using chisquare tests. In order to evaluate the trend of different laboratory parameters, the mean difference between nonSCD and SCD were compared across the age groups. Some mean differences were log transformed to improve 
visibility of parameters with high and low levels of the difference. Weighted logistic regression was used to determine association between binary response variable and explanatory variables (clinical and haematological factors) accounting for under representation of non-SCD individuals. A $p$-value $<0.05$ was considered to be statistically significant.

\section{Description of the MSC cohort}

The description included the age structure and pattern of enrollment. SCD diagnoses were classified into 2 categories: SCD was for SS and non-SCD for those with AS and AA. SCD were almost all $\beta^{S} / \beta^{S}$ with a small fraction of $S / \beta^{0}$ thalassaemia (estimated at $4 \%$ - unpublished data) and very rare $\beta^{S} / \mathrm{HPFH}$. SC or CC disease was not encountered. The age of patients was calculated at date of visit from the date of birth and three age group categories were defined: $<5,5-17$ and $\geq 18$ (adults) years. Description of clinical and laboratory features between SCD and non-SCD individuals was limited to individuals in age group 5-17 years for the following reasons; 1) $<5$ years age group is subject to considerable physiological changes; 2) $\geq 18$ years age group is a heterogeneous group and it is not clear whether it consists of individuals with mild disease who have survived the early mortality of severe disease but who are symptomatic and therefore attend $\mathrm{MNH}$ for healthcare. The ethnic group of an individual was from self-reported ethnicity which is patrilineal. If this information was missing, the ethnic group of the mother was used. We plotted the geographical distribution of SCD in Tanzania based on the ethnicity of the SCD cases registered at $\mathrm{MNH}$. The region where a particular ethnic group resides was used as a surrogate for the geographical distribution of SCD. Geographical coordinates of Tanzania and regional administrative boundaries were obtained from Global administrative boundaries website [26].

\section{Results}

During the 10-year period (2004-2013), 6397 individuals were enrolled, with 3751 (58.6\%) having SCD (> 95\% $\left.\beta^{S} / \beta^{S}\right) .3175(49.6 \%)$ were male and $2393(37.4 \%)$ were children aged $<5$ years (Table 1 ). The median age at testing was higher in non-SCD than in SCD individuals $(p<0.001)$, while the sex ratio was similar between the two groups and there was no difference among those who were coming outside Dar (proxy for distance) compared to those coming from outside Dar es Salaam (Table 1). As the MSC program continued there was a statistically significant $(p<0.001)$ decrease in age of SCD individuals enrolled; the median age decreased from 9.1 years [Interquartile range (IQR): $5.1-14.1$ ] in the first two years (2004-5) to 5.1 years (IQR: 2.3-11.1) during the last two years (2012-3).

The trend of enrolment on annual basis for the SCD patients is shown in Fig. 1a. The largest number of individuals

Table 1 Characteristics of individuals enrolled in the Muhimbili Sickle Cell Programme in Dar-es-Salaam, Tanzania

\begin{tabular}{|c|c|c|c|c|}
\hline Variable & Total & Non-SCD & SCD & $\begin{array}{l}\text { Test statistic } \\
\text { ( } p \text {-value) }\end{array}$ \\
\hline Number screened, n (\%) & 6397 & $2646(41.4)$ & 3751 (58.6) & \\
\hline Median age (IQR) & & $9.3(2.7-24.1)$ & $6.9(3.3-12.8)$ & $z=8.7(<0.001)$ \\
\hline \multicolumn{5}{|l|}{ Age group (\%) } \\
\hline $0-4$ & $2393(37.4)$ & $956(36.1)$ & $1437(38.3)$ & \multirow[t]{4}{*}{$x^{2}=346.7(<0.001)$} \\
\hline $5-17$ & $2592(40.5)$ & $813(30.7)$ & 1779 (47.4) & \\
\hline $18+$ & $1360(21.3)$ & $842(31.9)$ & $518(13.8)$ & \\
\hline Missing & $52(0.8)$ & $35(1.3)$ & $17(0.4)$ & \\
\hline \multicolumn{5}{|l|}{ Sex (\%) } \\
\hline Male & 3175 (49.6) & $1294(48.9)$ & $1881(50.1)$ & \multirow[t]{2}{*}{$x^{2}=0.96(0.328)$} \\
\hline Female & $3222(50.4)$ & $1352(51.1)$ & $1870(49.9)$ & \\
\hline \multicolumn{5}{|l|}{ Place of birth (\%) } \\
\hline Dar es Salaam & $3807(59.5)$ & $1445(54.6)$ & $2362(63.0)$ & \multirow[t]{3}{*}{$x^{2}=41.36(<0.001)$} \\
\hline Others & $2478(38.7)$ & $1143(43.2)$ & 1335 (35.6) & \\
\hline Missing & $112(1.8)$ & $58(2.2)$ & $54(1.4)$ & \\
\hline \multicolumn{5}{|l|}{ Place living } \\
\hline Dar es Salaam & $4446(69.5)$ & $1628(61.5)$ & 2818 (75.13) & \multirow[t]{3}{*}{$x^{2}=1.06(0.304)$} \\
\hline Others & $834(13.0)$ & $321(12.1)$ & $513(13.9)$ & \\
\hline Missing & $1117(17.5)$ & $697(26.2)$ & $420(11.2)$ & \\
\hline
\end{tabular}

Test statistics excluded missing values 

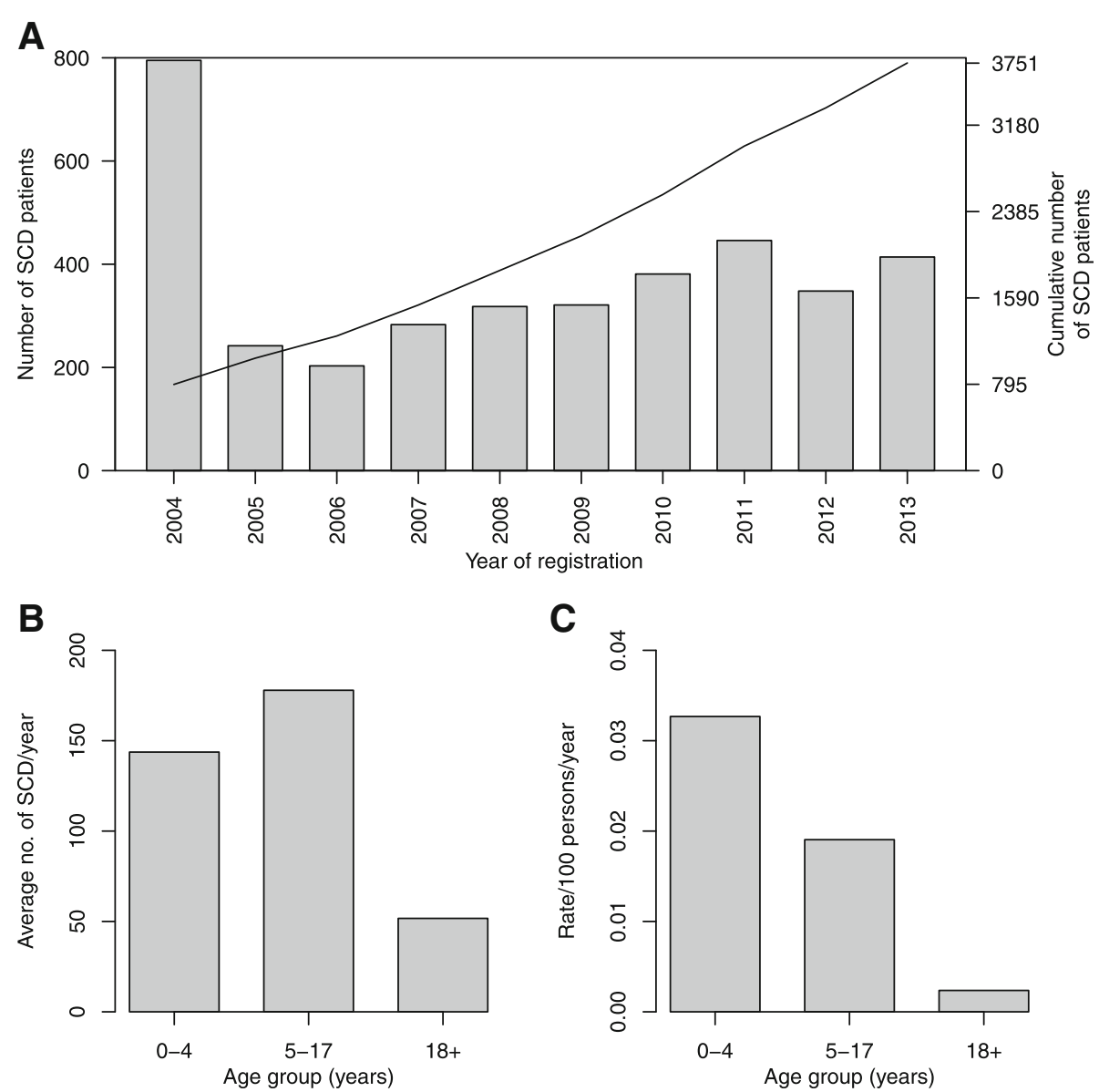

Fig. 1 Pattern of enrollment of individuals with SCD over a 10-year period. Bars and line shows the annual enrolment and cumulative number of enrolment respectively (a). Average number of individuals enrolled per year by age group (b) and rate of enrolment per 100 persons per year by age group (c)

with SCD was enrolled, not surprisingly, during the first year of the program. Subsequently, the annual number enrolled was relatively steady, with the median number enrolled per month being 62 (IQR: 18.5-92). On average, the middle age group (5-17 years) was most abundantly represented (Fig. 1b). However, the rate of enrollment weighted for population size was highest amongst the youngest $(<5$ years: Fig. $1 \mathrm{c})$.

\section{Geographical distribution of SCD in Tanzania based on ethnicity of participant}

Enrollment is a composite result of the variable prevalence of the $\mathrm{Hb} \mathrm{S}$ gene, of migration patterns to Dar-es-Salaam and referral practices to $\mathrm{MNH}$. With that proviso, we note that regions with the highest SCD cases were those along the coast ( $>10$ cases per 100,000 people), the NorthEastern part, which include regions of Coast, Tanga and Zanzibar and along the Lake Victoria zone (Tabora, Shinyanga, Kagera and Mara) with prevalence ranging from 5 to 12 cases per 100,000 people (Fig. 2). In contrast, Arusha, Manyara, Kilimanjaro and Rukwa regions had the lowest representation of SCD $(<2$ cases per 100,000).

\section{Comparison of clinical and laboratory features of individuals (5 to 17 years) with and without SCD}

Table 2 compares the clinical and laboratory parameters between non-SCD and SCD individuals aged 5-17 years for the reasons outlined under Methods section. Compared to non-SCD, the SCD group had statistically significant higher pulse rate and mean body temperature, but lower levels of blood pressure and peripheral oxygen saturation. The prevalence of low oxygen saturation $(<$ $95 \%$ ), jaundice and splenomegaly was significantly higher in SCD than in non-SCD group. Regarding laboratory features, SCD is a well-defined disease for which there is no a priori appropriate control group. Comparison of SCD and non-SCD individuals enrolled in the MSC programme, we find that all parameters were significantly different. The SCD group had a significantly lower 


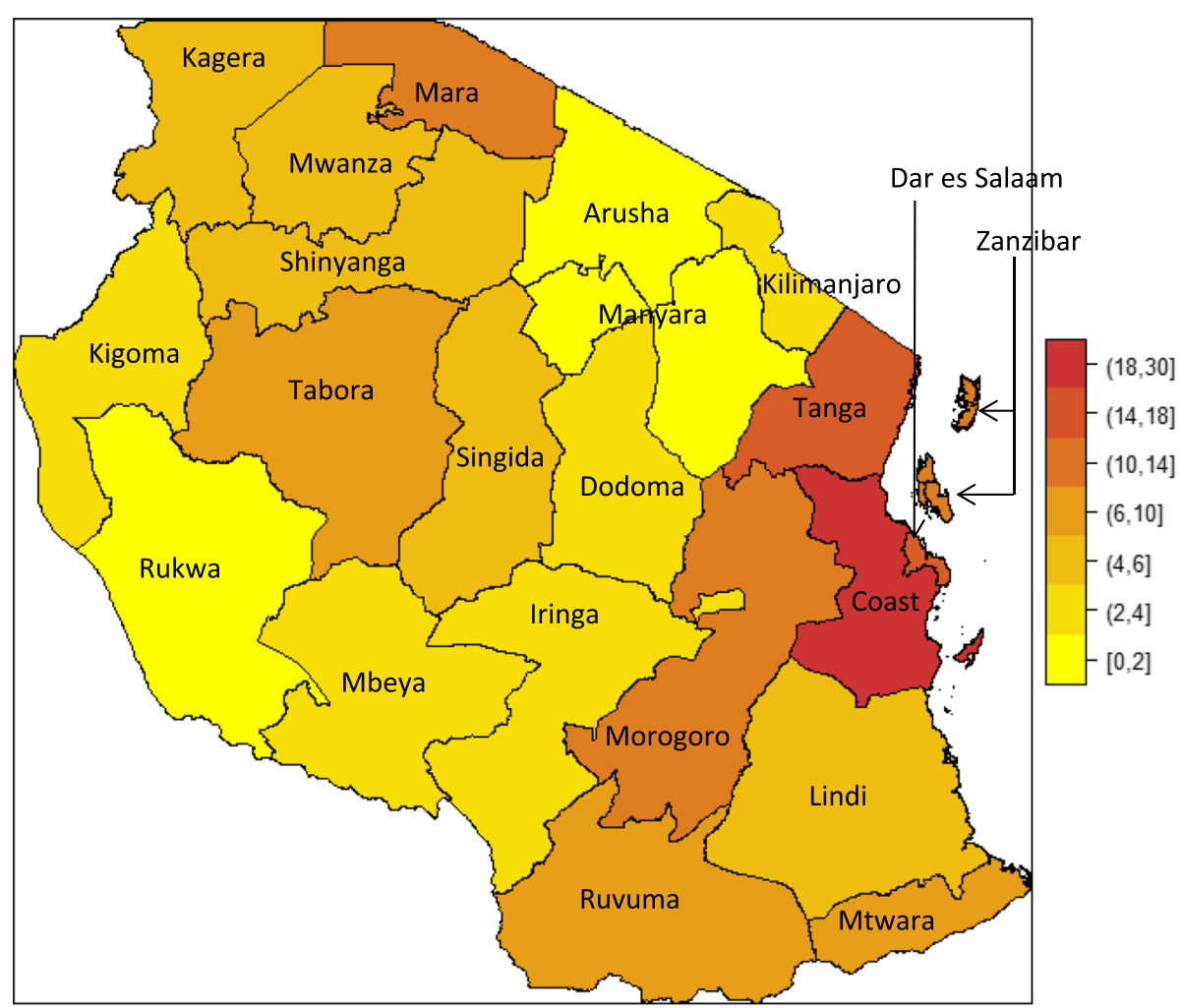

Fig. 2 Geographical distribution of risk of sickle cell disease in Tanzania. Note: Prevalence is expressed (per 100,000) as the ratio of individuals with SCD enrolled in the MSC programme from a particular region to the total population of that region. Ethnicity is self-reported based on patrilineal tribe

$\mathrm{Hb}(\mathrm{g} / \mathrm{dl})$ (7.4 vs 10.6), alkaline phosphatase and creatinine but higher levels of reticulocyte count, RDW, HbF, $\mathrm{MCV}, \mathrm{MCH}, \mathrm{WBC}$, platelet count, total, direct and indirect bilirubin, aspartate transaminase, and lactate dehydrogenase. Similar trends for parameter levels were observed even when analysis was extended for all age groups, Fig. 3. The trends of mean difference were similar across the age groups, except for $\mathrm{MCHC}$ (non-SCD aged $<5$ years had higher levels) and ALP (non-SCD aged $>18$ years had lower levels) when compared to other groups. Only mean difference for platelets, ALP and creatinine for children $<5$ years were not significantly different between the non-SCD and SCD groups $(p>0.05)$.

\section{Clinical and laboratory features of SCD patients by age group}

Evaluation of the clinical and laboratory features in three different age groups within the SCD population is presented in Table 3 and Fig. 4. There were statistically significant differences between the three age groups and interestingly, many of the parameters showed monotonic trends with increasing age. Notably, children aged 0-4 years had a significantly higher pulse rate and prevalence of palpable spleen, whilst peripheral oxygen saturation was lower in older SCD patients and prevalence of jaundice increased with age. The blood pressure (both systolic and diastolic) was significantly higher in the older SCD populations. For 1165 patients (31\%), we obtained medical history on the causes of hospitalization in the 12 month period preceding enrollment (Fig. 5). Overall, the three commonest causes of hospitalization were pain, fever (including malaria) and severe anemia. Severe anaemia was the leading cause in children $<18$ years $(36.9 \%$ in $0-4$ and 30.7 in 5-17 years), whereas pain was the main cause amongst adults aged $\geq 18$ years (43.2\%). Pain (12.9\%), fever $(12.0 \%)$ and malaria (11.2\%) contributed equally in children below 5 years, while in children aged 5-17 years pain $(27.4 \%)$ was the second contributing factor. Out of 469 patients who were admitted with symptoms of severe anaemia as the primary cause, severe anaemia ( $\mathrm{hb}<5$ g.dL) was confirmed in $13.3 \%$ of the patients, 36 (7.7\%) had pain, while only one patient had jaundice. Contrarily, of patients with $\mathrm{Hb}$ results (338) among those admitted with pain as the primary cause, only 11 (3.2\%) had confirmed severe anaemia, while only three (out of 388) had jaundice.

The levels of $\mathrm{Hb}, \mathrm{MCV}, \mathrm{MCH}$ and $\mathrm{MCHC}$ showed a slight but significant upward trend, whereas RDW 
Table 2 Clinical and laboratory features of SCD and non-SCD individuals aged 5-17 years

\begin{tabular}{|c|c|c|c|c|c|}
\hline & \multicolumn{2}{|c|}{ Non-SCD (HbAA, AS) } & \multicolumn{2}{|c|}{ SCD (HbSS) } & \multirow{2}{*}{$\begin{array}{l}\text { Test statistic } \\
\text { (p-value) }\end{array}$} \\
\hline & $n$ & Estimate & $n$ & Estimate & \\
\hline \multicolumn{6}{|l|}{ Clinical features } \\
\hline Age (years) (Median, IQR] & 662 & $9.91(7.1-13.1)$ & 1010 & $9.5(7.1-12.5)$ & $x^{2}=5.37(0.020)$ \\
\hline Pulse rate (beats/min) [mean, 95\%Cl] & 680 & $90.5(89.2-91.8)$ & 1585 & $94.0(93.2-94.7)$ & $t=-4.79(<0.001)$ \\
\hline Temperature $\left({ }^{\circ} \mathrm{C}\right)[$ mean, $95 \% \mathrm{Cl}]$ & 694 & $36.0(35.8-36.4)$ & 1628 & $36.5(36.4-36.5)$ & $t=-3.63(<0.001)$ \\
\hline Systolic Blood pressure $(\mathrm{mm} / \mathrm{Hg})$ [mean, 95\% $\mathrm{Cl}]$ & 685 & $107.5(105.8-109.2)$ & 1462 & $104.9(104.1-105.6)$ & $t=3.31(0.001)$ \\
\hline Diastolic blood pressure(mm/Hg) [mean, 95\%Cl] & 684 & $67.5(66.3-68.7)$ & 1461 & $63.9(63.3-64.5)$ & $t=5.96(<0.001)$ \\
\hline Peripheral Oxygen saturation,(median, IQR) & 662 & $99(98,100)$ & 1010 & $98(96,100)$ & $\mathrm{Z}=11.78(p<0.001)$ \\
\hline Peripheral Oxygen desaturation, [n/N (\%)] & & $50 / 663(7.5)$ & & $162 / 1009(16.1)$ & $x^{2}=26.2(p<0.001)$ \\
\hline Jaundice, [n/N (\%)] & & 45/309 (14.6) & & $943 / 1541(61.2)$ & $x^{2}=224.4(p<0.001)$ \\
\hline Palpable Spleen, [n/N (\%)] & & $25 / 451(5.54)$ & & 201/1552 (12.9) & $x^{2}=19.16(<0.001)$ \\
\hline \multicolumn{6}{|l|}{ Laboratory features $(95 \% \mathrm{Cl})$} \\
\hline Hemoglobin $(\mathrm{Hb})(\mathrm{g} / \mathrm{dL})$ & 759 & $10.6(10.4-10.8)$ & 1653 & $7.4(7.3-7.4)$ & $t=32.34(<0.001)$ \\
\hline Fetal hemoglobin (HbF) & 422 & $1.7(0.91-2.5)$ & 803 & $6.8(6.4-7.1)$ & $t=-11.7(<0.001)$ \\
\hline Mean Cell Volume (MCV) (fL) & 762 & $75.2(74.3-76.0)$ & 1653 & $79.7(79.1,80.2)$ & $t=-8.72(<0.001)$ \\
\hline Mean Cell Hb (MCH) (pg) & 743 & $24.5(24.2-24.7)$ & 1628 & $26.0(25.8-26.2)$ & $t=-9.12(<0.001)$ \\
\hline Mean Cell Hb Concentration(MCHC) (g/dL) & 760 & $32.2(32.1-32.3)$ & 1632 & $32.5(32.4-32.6)$ & $t=-4.00(<0.001)$ \\
\hline Red Cell Distribution width (RDW) (\%) & 761 & $17.3(17.0-17.6)$ & 1636 & $22.6(22.4-22.8)$ & $t=-31.49(<0.001)$ \\
\hline Reticulocyte (\%) & 294 & $7.1(6.0-8.4)$ & 583 & $11.2(10.6-11.8)$ & $t=-6.15(<0.001)$ \\
\hline Absolute reticulocyte $\left(\times 10^{9} / \mathrm{L}\right)$ & 274 & $0.26(0.21-0.31)$ & 563 & $0.33(0.32-0.36)$ & $t=-2.42(0.016)$ \\
\hline White Blood Cells (WBC) $\left(\times 10^{9} / \mathrm{L}\right)$ & 868 & $9.1(8.6-9.5)$ & 1582 & $15.6(15.2-15.9)$ & $t=-23.5(<0.001)$ \\
\hline Platelets $(\mathrm{PLT})\left(\times 10^{9} / \mathrm{L}\right)$ & 763 & $349.3(336.5-362.04)$ & 1652 & $444.4(434.5-454.3)$ & $t=-11.55(<0.001)$ \\
\hline Bilirubin total $(\mu \mathrm{mol} / \mathrm{L})$ & 271 & $10.3(9.3-11.4)$ & 930 & $59.7(56.7-62.8)$ & $t=-30.72(<0.001)$ \\
\hline Bilirubin direct $(\mu \mathrm{mol} / \mathrm{L})$ & 188 & $3.0(2.5-3.6)$ & 875 & $14.4(13.6-15.2)$ & $t=-19.08(<0.001)$ \\
\hline Bilirubin indirect $(\mu \mathrm{mol} / \mathrm{L})$ & 179 & $8.6(7.4-9.9)$ & 865 & $42.1(39.5-44.8)$ & $t=-20.52(<0.001)$ \\
\hline Aspartate AminoTransferase (AST) (U/L) & 295 & $36.1(32.6-39.5)$ & 949 & $52.0(49.7-54.5)$ & $t=-7.69(<0.001)$ \\
\hline Alkaline phosphatase (ALP) (IU/L) & 294 & $353.6(329.5-377.7)$ & 953 & $267.5(258.8-276.5)$ & $t=6.58(<0.001)$ \\
\hline Lactate dehydrogenase (LDH) (U/L) & 328 & $593.8(548.0-639.5)$ & 569 & $971.6(932.0-1011.2)$ & $t=-12.28(<0.001)$ \\
\hline Creatinine ( $\mu \mathrm{mol} / \mathrm{L})$ & 292 & $46.8(44.7-48.9)$ & 949 & $37.6(36.6-38.5)$ & $t=8.36(<0.001)$ \\
\hline
\end{tabular}

decreased with age. Reticulocyte counts were elevated in all age groups but they decreased with age. There were significant differences in the WBC counts with counts decreasing with age whereas platelet counts increased with age. Total, direct and indirect bilirubin all increased significantly with age $(p<0.001)$. AST and ALP decreased with age, however the decrease was only significant for ALP $(p<0.001)$.

\section{Discussion}

This is the first study that provides a description of the spectrum of SCD in Africa from one of the largest single-centre SCD cohorts in the world. There has been relatively limited information about the spectrum of SCD in Africa when compared to information available from studies outside Africa. Most large series have been from the US, Jamaica and Europe which have involved study populations exceeding 2000 patients with prospective follow up for at least 10 years [4, 27, 28]. In Africa, there has been an increase in the number of similar studies, although the sample size has been smaller (500 to 1000 individuals) and duration has been shorter (up to 5 years) [7-9].

In the first two years of the MSC program, most of the patients enrolled were those already receiving clinical care at $\mathrm{MNH}$, with the majority in the $5-17$ year age group (Fig. 1b). This was therefore likely to be a survival cohort and highlighted two unmet needs: the urgency of newborn screening and of strengthening SCD pediatric care. The peak of ongoing enrollment was in 2011 that coincided with optimal number of personnel, weekly clinics and the doctor to patient ratio. This is also the period that the MSC program started working with the Ministry of Health of Tanzania with the aim of strengthening SCD 


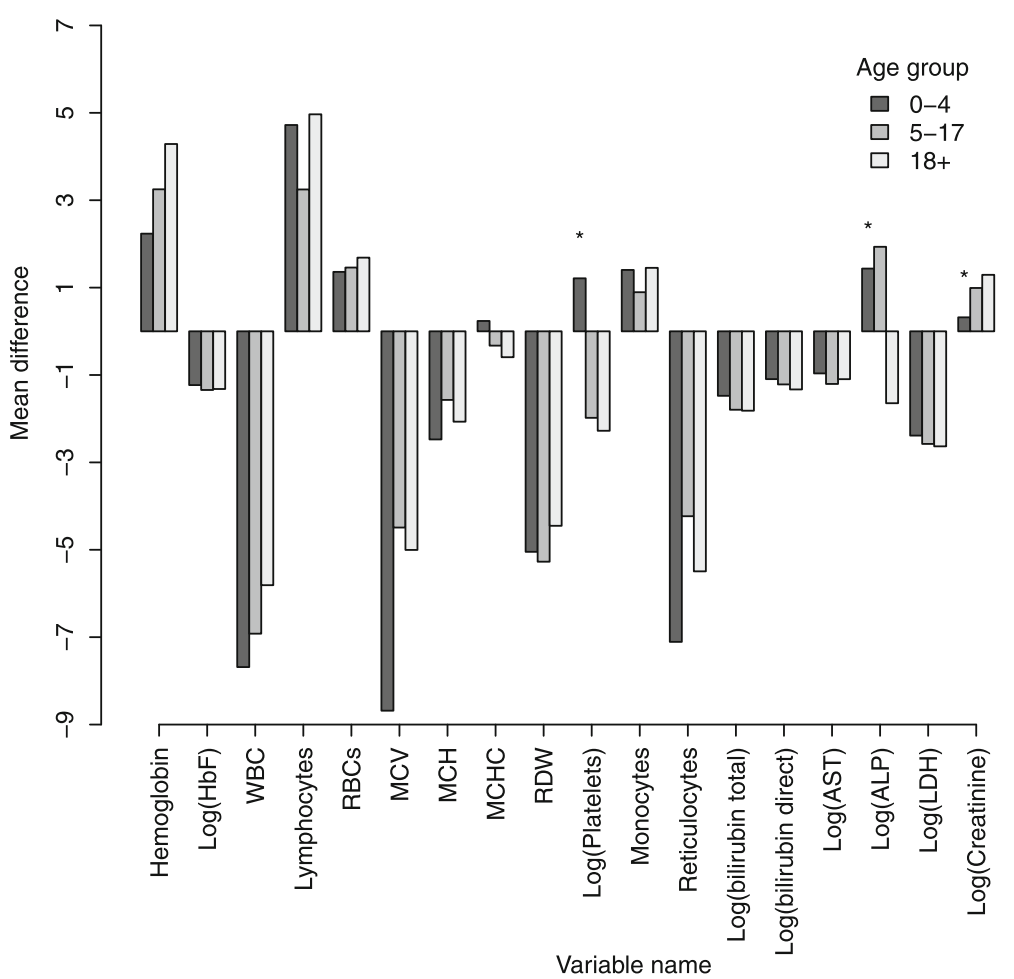

Fig. 3 Distribution of mean difference of hematological parameters between non-SCD and SCD individuals by age-group. Only mean difference for platelets, ALP and creatinine for children $<5$ years were not significant difference $\left(^{*}\right)$ between the non-SCD and SCD $(p>0.05)$

services throughout the country, as part of the noncommunicable diseases (NCD) program [29]. The agespecific rate of enrollment (Fig. 1c) shows a marked decrease with age: this suggests, unfortunately, a high rate of early mortality in the younger age group, which we have previously reported [16]. At the same time, it is important to note that $518 \mathrm{SCD}$ individuals were aged $\geq 18$ years, providing evidence of survival into adulthood and highlighting the need for adult services. It should be noted that the adult SCD population may comprise two distinct groups: (a) those with severe disease seeking healthcare due to acute and chronic complications, sometimes related to end-organ dysfunction; (b) those with relatively mild disease, who survived childhood.

We report heterogeneity in the geographical prevalence of SCD in Tanzania. The enrollment into the MSC program of patients from different parts of Tanzania will have been influenced by ease of access for residents in regions closer to $\mathrm{MNH}$ and/or by socio-economic status, whereby those with higher income are more likely to come to MNH. Nevertheless, it is interesting that the highest numbers were from the coastal regions, including Zanzibar, and from regions around Lake Victoria, despite the long distance between these regions and Dar-es-Salaam. These areas are known to have high malaria transmission On the other hand, there were lower numbers from regions close to Dar-es-Salaam such as
Iringa, Manyara, Lindi, Kilimanjaro, where malaria transmission is less. It is noteworthy that, in spite of the ascertainment bias just mentioned, these data agree with previous estimates of $\beta^{S}$ gene frequencies in Tanzania [1], although further research is needed to evaluate the genetic and environmental factors, other than malaria, that influence disease prevalence. Detailed micro-mapping of SCD prevalence will also aid planning of optimal health services, targeting areas with high prevalence.

In the initial analysis of features of SCD (Table 2) we compared SCD with non-SCD (HbAA and HbAS) individuals enrolled at the same time. The purpose of this comparison was not to illustrate the differences between SCD and non-SCD, as by definition SCD patients, who have life-long haemolytic anaemia would be discernably different from the non-SCD group. We anticipated that several parameters such as haemoglobin, reticulocytes and bilirubin levels would be higher. What we could not have predicted a priori was that the mean value of all parameters measured would be significantly different even though, in many cases by a small measure (but, given the large numbers of individuals tested, in nearly all cases the $P$-value was less than 0.001 ). The SCD group when compared to non-SCD group had higher prevalence of jaundice and higher pulse rate. The blood pressure was lower in the SCD group, similar to previous reports of a low prevalence of hypertension in this SCD population as 
Table 3 Clinical and laboratory features of SCD individuals in 3 age categories ( $<5$ years; $5-17$ years and $\geq 18$ years)

\begin{tabular}{|c|c|c|c|c|c|c|}
\hline \multirow[t]{2}{*}{ Variable } & \multirow[t]{2}{*}{$\mathrm{N}$} & \multicolumn{3}{|c|}{ Age group (years) } & \multirow[t]{2}{*}{ Test statistic } & \multirow[t]{2}{*}{$P$-value } \\
\hline & & $0-4$ years & $5-17$ years & $\geq 18$ years & & \\
\hline \multicolumn{7}{|l|}{ Clinical features } \\
\hline Age (years) (Median,IQR] & 3265 & $2.5(1.4-3.8)$ & $9.5(7.1-12.5)$ & $23.7(20.3-29.5)$ & & \\
\hline Pulse rate (beats/min) [mean, sd] & 3238 & $110.11 \pm 23.1$ & $94.0 \pm 15.1$ & $83.5 \pm 13.7$ & $446.3^{\downarrow}$ & $<0.001$ \\
\hline Temperature $\left({ }^{\circ} \mathrm{C}\right)[$ mean, sd] & 3413 & $36.5 \pm 1.5$ & $36.5 \pm 1.0$ & $36.3 \pm 1.8$ & $3.16^{\downarrow}$ & 0.042 \\
\hline Systolic Blood pressure $(\mathrm{mm} / \mathrm{Hg})[$ mean, sd] & 2993 & $97.9 \pm 24.2$ & $104.9 \pm 14.4$ & $116.6 \pm 16.9$ & $160.8^{\uparrow}$ & $<0.001$ \\
\hline Diastolic blood pressure $(\mathrm{mm} / \mathrm{Hg})[$ mean, sd] & 2993 & $58.8 \pm 16.4$ & $63.9 \pm 11.5$ & $70.7 \pm 12.2$ & $127.9^{\uparrow}$ & $<0.001$ \\
\hline Peripheral Oxygen saturation,(median, IQR) & 2713 & $99(97-100)$ & $98(96-100)$ & $98(96-99)$ & 13.7 & 0.001 \\
\hline Peripheral Oxygen desaturation, [n/N (\%)] & 2713 & $170(15.4)$ & $200(16.4)$ & $58(14.9)$ & 0.654 & 0.721 \\
\hline Jaundice, [n/N (\%)] & 3171 & $542(45.0)$ & $943(61.2)$ & $292(68.4)$ & $102.0^{\uparrow}$ & $<0.001$ \\
\hline Pallor, [n/N (\%)] & 3102 & $447(37.8)$ & $573(38.1)$ & $142(34.5)$ & 2.06 & 0.357 \\
\hline Palpable Spleen, [n/N (\%)] & 3242 & $192(15.5)$ & $201(12.9)$ & $21(4.7)$ & $35.0^{\downarrow}$ & $<0.001$ \\
\hline \multicolumn{7}{|l|}{ Laboratory features } \\
\hline Hemoglobin $(\mathrm{Hb})(\mathrm{g} / \mathrm{dL})$ & 3456 & $7.2 \pm 1.4$ & $7.4 \pm 1.4$ & $7.6 \pm 2.1$ & $10.24^{\uparrow}$ & $<0.001$ \\
\hline Fetal hemoglobin (HbF) & 1942 & $12.2 \pm 7.9$ & $6.8 \pm 5.63$ & $5.6 \pm 4.7$ & $182.9^{\downarrow}$ & $<0.001$ \\
\hline Mean Cell Volume (MCV) (fL) & 3454 & $78.1 \pm 11.1$ & $79.7 \pm 11.7$ & $82.4 \pm 13.8$ & $22.49^{\uparrow}$ & $<0.001$ \\
\hline Mean Cell Hemoglobin (MCH) (pg) & 3406 & $24.6 \pm 3.6$ & $26.0 \pm 4.1$ & $27.2 \pm 5.0$ & $84.11^{\uparrow}$ & $<0.001$ \\
\hline Mean Cell Hemoglobin Concentration(MCHC) (g/dL) & 3419 & $31.4 \pm 1.7$ & $32.5 \pm 2.1$ & $32.9 \pm 2.1$ & $169.58^{\uparrow}$ & $<0.001$ \\
\hline Red Cell Distribution width (RDW) (\%) & 3440 & $23.8 \pm 4.0$ & $22.6 \pm 3.8$ & $21.1 \pm 4.4$ & $81.22^{\downarrow}$ & $<0.001$ \\
\hline Reticulocyte (\%) & 1212 & $13.3 \pm 7.8$ & $11.3 \pm 7.5$ & $10.3 \pm 7.0$ & $14.45^{\downarrow}$ & $<0.001$ \\
\hline Absolute reticulocyte $\left(\times 10^{9} / \mathrm{L}\right)$ & 1153 & $0.40 \pm 0.35$ & $0.33 \pm 0.32$ & $0.33 \pm 0.62$ & $5.06^{\downarrow}$ & 0.006 \\
\hline White Blood Cells (WBC) $\left.\left(\times 10^{9} / L\right)\right)$ & 3238 & $19.2 \pm 8.3$ & $15.6 \pm 6.6$ & $12.4 \pm 5.2$ & $170.95^{\downarrow}$ & $<0.001$ \\
\hline Platelets (PLT) $\left.\left(\times 10^{9} / L\right)\right)$ & 3453 & $377.6 \pm 19.8$ & $444.4 \pm 205$ & $450.7 \pm 213.2$ & $45.92^{\uparrow}$ & $<0.001$ \\
\hline Log(Bilirubin total $(\mu \mathrm{mol} / \mathrm{L}))$ & 1706 & $3.62 \pm 0.74$ & $4.11 \pm-.78$ & $4.16 \pm 0.81$ & $76.3^{\uparrow}$ & $<0.001$ \\
\hline Log(Bilirubin direct $(\mu \mathrm{mol} / \mathrm{L}))$ & 1561 & $2.45 \pm 0.82$ & $2.73 \pm 0.80$ & $2.79 \pm 0.90$ & $21.3^{\uparrow}$ & $<0.001$ \\
\hline Log(Bilirubin indirect $(\mu \mathrm{mol} / \mathrm{L}))$ & 1545 & $3.28 \pm 0.83$ & $3.76 \pm 0.92$ & $3.80 \pm 0.91$ & $47.9^{\uparrow}$ & $<0.001$ \\
\hline Aspartate Aminotransferase (AST) (U/L) & 1750 & $53.2 \pm 31.5$ & $52.0 \pm 38.3$ & $48.2 \pm 39.8$ & 1.64 & 0.193 \\
\hline Alkaline phosphatase (ALP) (IU/L) & 1758 & $314.2 \pm 147.2$ & $267.5 \pm 140.5$ & $179.2 \pm 156.1$ & $75.69^{\downarrow}$ & $<0.001$ \\
\hline Lactate dehydrogenase (LDH) (U/L) & 1196 & $962.2 \pm 428.0$ & $971.6 \pm 481.1$ & $918.4 \pm 686.9$ & $0.78^{\uparrow}$ & 0.461 \\
\hline $\log (C r e a t i n i n e(\mu \mathrm{mol} / \mathrm{L}))$ & 1744 & $3.49 \pm 0.36$ & $3.23 \pm 0.39$ & $3.94 \pm 0.43$ & $117.0^{\uparrow}$ & $<0.001$ \\
\hline
\end{tabular}

Variables (Hypoxia, Jaundice, Pallor, Palpable Spleen) were compared using $X^{2}$ test, while rest of variables were compared using F-test. ${ }^{\downarrow}$ Effect decrease with increase in age while ${ }^{\uparrow}$ indicate increase of the effect with age

well as in the USA $[23,30]$. The peripheral oxygen saturation was significantly lower in SCD: the difference was small, but in $16.1 \%$ of patients it was below $95 \%$. This may be clinically signficant because it is related to the severity of anaemia [31] and to high 2,3-DPG levels, which increases deoxy-Hb S polymerization and sickling [32]. We and others have previously observed that low oxygen saturation is associated with increased cerebral blood flow velocity $[33,34]$, and higher risk of neurological complications $[35,36]$. It was observed that there were low levels of red cell indices $(\mathrm{MCV}, \mathrm{MCH})$, which may be attributed in part to the high frequency of $\alpha$-thalassaemia in this population (about 40\% heterozygotes [37]): however, there is no a priori reason why this frequency should be any different in SCD versus non-SCD.

\section{Novel information}

Most studies of SCD have focused on children and adults separately, reflecting the fact that most healthcare systems have dedicated but separate paediatric and adult services. The MSC program, instead, aimed to integrate the care of SCD patients across their life span. First, we noted that pain, infection and anaemia were the three most common causes of hospital visits (Fig. 5): but whereas in children the most common cause was anaemia, adults were more affected by painful episodes. 

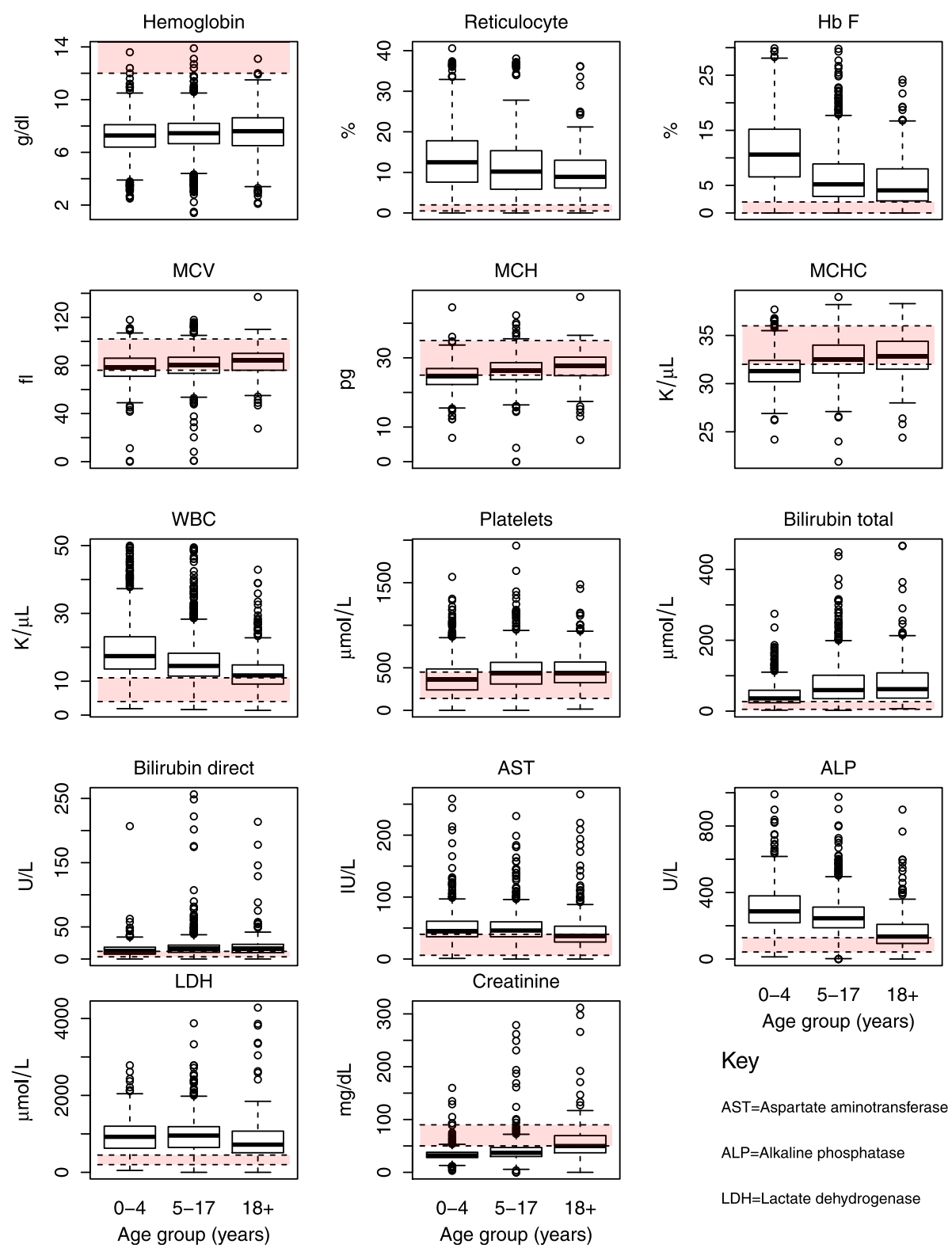

Key

AST $=$ Aspartate aminotransferase

ALP=Alkaline phosphatase

$\mathrm{LDH}=\mathrm{Lactate}$ dehydrogenase

Fig. 4 Distribution of selected laboratory parameters of SCD individuals by age-group

This is similar to findings in other series, where $50 \%$ of adults experience painful episodes compared to only $10 \%$ in children [38]. Next, we analyzed by age groups all other data over the entire age span from infancy to adulthood. To our knowledge, this is one of the first studies in which such a systematic analysis has been attempted. Here we will focus only on a few observations which we think are important. First, mean level of $\mathrm{Hb}$ increased with age, though only slightly, and this was associated with a decrease in the mean reticulocyte count. This correlation is expected, as the increased reticulocyte count reflects a normal compensatory erythropoietic response to anaemia. The decreased reticulocyte count in older patients with SCD may also have reflected reduced erythropoietin levels in the context of the onset of chronic kidney disease, as evidenced by the higher creatinine in the older age group. An alternative explanation may possibly be a direct effect of vaso-occlusive events on the bone marrow resulting in reduced erythropoiesis with impaired reticulocyte production. Second, with respect to $\mathrm{HbF}$, we expected that the mean $\mathrm{HbF}$ level would be highest in the youngest age group, since the physiological decrease in $\mathrm{HbF}$ from the level of about $80 \%$ at birth is much delayed in SS children compared to controls - in at least the first 30 months of life [39]. However, the further decrease in $\mathrm{HbF}$ in the 


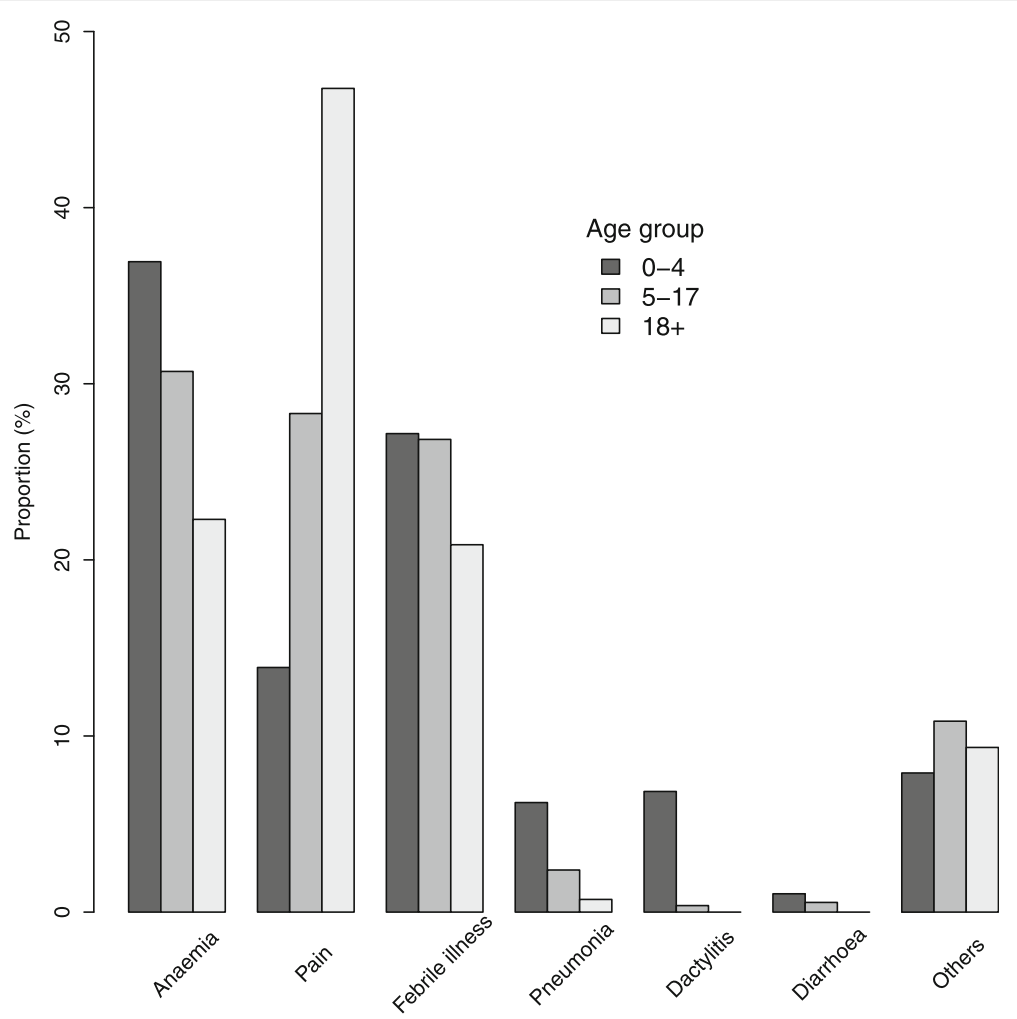

Fig. 5 Conditions associated with hospital visits in the 12 months preceding enrolment visit

transition from the 5-17 age group to adulthood is somewhat paradoxical, because one would have expected that SCD patients with higher HbF would be, if anything, favored in terms of survival: since $\mathrm{HbF}$ was seen not to predict mortality in our previous work [33], this finding requires further research. Third, the mean values of red cell indices ( $\mathrm{MCV}, \mathrm{MCH}, \mathrm{MCHC})$ were lower in the younger age group which, in line with the fall in RDW with age, may mean that iron deficiency anemia is more common in the youngest patients (it is indeed common in Tanzania in the $<5$ age group). Low MCV and $\mathrm{MCH}$ may also result from $\alpha$-thalassaemia, which is generally regarded as an ameliorating factor in SCD; however, from these data and our previous work [33], low MCV does not seem to confer a survival advantage. Fourth, the mean WBC count decreased with age: which may suggest that the prevalence of infection is higher in children and decreases with age. However, the downward trend in WBC counts may also mean that the older age group is representative of less severe disease. In contrast, the mean platelet count increased with age, probably reflecting a decrease in splenic function: this explanation is supported by a lower prevalence of palpable spleen in the older age groups. The age-specific patterns in the level of WBC counts and platelets warrant further research, as the role of these blood components in the pathophysiology of SCD is being increasingly recognized [40]. Fifth, the mean level of bilirubin increases with age, in keeping with the observation that prevalence of jaundice increased with age. This may be explained by an increase in the rate of extravascular haemolysis; liver dysfunction is less likely since there was a decrease in the mean levels of ALP and AST (albeit not statistically significantly with respect to AST). We must also consider that the higher levels of ALP in the younger age groups could be related to increased bone tissue turnover associated with growth. A striking observation was the high level of LDH (more than 3 times the upper limit of normal) in all age groups, which suggests a significant level of intravascular haemolysis, although cardiac and liver dysfunction may also contribute. Further research is required to quantitate the age-specific rate of haemolysis and whether there is a change with age in the relative rates of intravascular versus extravascular haemolysis. Finally, the mean creatinine level increased with age, although most values remained within the normal range. The creatinine level on its own is not a sensitive index of early renal disease, but one wonders whether in individual cases the trend of creatinine with age may be a prelude to renal insufficiency, a known complication of SCD. It should be noted that the age-related trends in clinical and laboratory parameters in this report were also reported by Aliyu et al. [41] in Nigeria (208 individuals with SCD; Youngest 10 years; 7\% > 35 years). 
In one of the first systematic studies of SCD patients, Nagel and colleagues [42] noted that the $\beta^{S}$ haplotype may account for the great variability in the clinical symptomatology and severity of SCD. In this population in Tanzania, this layer of heterogeneity is largely removed, since nearly all patients are homozygous for the Central African Republic (CAR) haplotype (previously referred to as Bantu haplotype) [43]: However, the spread of values remains just as great (Fig. 4); for example, the mean hematocrit level that Nagel et al. [42] reported for SS patients with CAR haplotype was 23.1, which corresponds almost to the mean $\mathrm{Hb}$ of 7.4 in the Tanzania population with the same haplotype, although the range in Tanzania is wider. Although the $\beta$-globin haplotype is regarded as a major determinant of $\mathrm{HbF}$ production, we found (Fig. 4) a markedly skewed distribution, whereby the top $2.5 \%$ of patients had $\mathrm{HbF}$ values some 4 times higher than the mean. Genomic studies conducted in SCD in Tanzania have already reported variability in prevalence of and co-existence of genomic loci that influence $\mathrm{HbF}, \alpha$-thalassemia, and G6PD levels [25, 37]. Further research is required, and is ongoing, to increase understanding in the complex interplay of genetic, environmental and socio-economic factors influencing variability of disease spectrum [44].

\section{Limitations}

Because enrolment into the SCD cohort was hospitalbased, the study may not have captured individuals with mild disease. The non-SCD group was not a populationbased age- and sex-matched control group: rather, it was a 'convenient' comparison group consisting of patient family members and of individuals enrolled among those suspected to have SCD: hence they may have other medical conditions. Indeed, the clinical and laboratory features were often not normal. We did not separate controls with HbAA from those with HbAS. This is broadly justified because sickle cell trait subjects have no cells containing exclusively $\mathrm{HbS}$ and are haematologically normal. However it is possible that some parameters may differ in AA versus AS subjects: this requires further study. Finally, the work reported here is that from cross-sectional analysis of the enrolment cohort. Although the study was conducted over a 10 year period, we are not yet presenting longitudinal data.

\section{Conclusion}

This work demonstrates that in an African country it is feasible to enrol, across all age groups, a large number of SCD patients and to assess in considerable detail their clinical and laboratory manifestations. Not surprisingly, in first approximation the clinical spectrum of SCD is similar to that observed elsewhere. However, the age distribution is different, unfortunately reflecting, at least in part, early mortality and delayed diagnosis due to the absence of newborn screening. The prevalence of severe anaemia is high, probably reflecting less blood transfusion treatment and other environmental factors, including malaria and a higher rate of bacterial infection.

SCD has been recognized as a major public health problem: as such, it was essential for us to establish not just its size, but also its spectrum. While this paper was in its first draft the first SCD patient successfully cured with gene therapy was reported [45] and the American Society of Hematology issued a Call to Action on Sickle Cell Disease. We feel strongly that in Africa the transition from taking stock to taking action is overdue: we must implement urgently beneficial measures such as newborn screening, infection prophylaxis, optimization of blood transfusion practice and the use of hydroxyurea; and we must also contribute to research on potentially curative treatments.

\section{Abbreviations \\ AA: Haemoglobin AA (normal haemoglobin); ALP: Alkaline phosphatase; AS: Haemoglobin AS (sickle cell trait); AST: Aspartate aminotransferase; BIL- D: Bilirubin direct; BIL-T: Bilirubin total; BT: Blood transfusion; CC: Haemoglobin CC; CRF: Case report forms; EDTA: Ethylenediaminetetraacetic acid; Hb: Haemoglobin; HbF: Fetal haemoglobin; HPFH: Hereditary persistence of fetal haemoglobin; HPLC: High performance Liquid Chromatography; IQR: Inter quartile range; LDH: Lactate dehydrogenase; MCH: Mean corpuscular haemoglobin; MCHC: Mean corpuscular haemoglobin Concentration; MCV: Mean corpuscular volume; MNH: Muhimbili National Hospital; MSC: Muhimbili Sickle cell; MUHAS: Muhimbili University of Health and Allied Sciences; NCD: Non-Communicable Diseases; PLT: Platelet count; RBC: Red blood cell count; RDW: Red cell distribution width; SC: Haemoglobin SC; SCD: Sickle cell disease; SS: Haemoglobin SS; UK: United Kingdom; USA: United States of America; WBC: White blood cell; WHO: World Health Organization; $\beta^{\text {S}}$ : Beta globin}

\section{Acknowledgements}

We thank the patients and staff of Muhimbili National Hospital and Muhimbili University of Health and Allied Sciences. We thank the following individuals: Data collection: Albert N Komba, Critical comments on statistical analysis: Neal O Jeffries, Nancy L Geller from NHLBI, NIH. Mentorship and support: Thomas Williams, Kevin Marsh, Kisali Pallangyo, Ephata Kaaya.

\section{Funding}

This work was supported by the Wellcome Trust, UK (Fellowship Julie Makani 072064, 093727; Project grant 080025; Strategic award 084538; Principal Wellcome Trust Fellowship R W Snow 103602) and Government of United Republic of Tanzania.

\section{Availability of data and materials}

The datasets used and/or analysed during the current study are available from the corresponding author on reasonable request.

\section{Authors' contributions}

Contribution: JMa, RWS, CRN, DR, MA, SLT, SEC conceived and designed the study; JMa, FT, AM, DS, SR, CK, EO and EM patients care and clinical data collection; SN and JMg performed sample processing and laboratory analyses; RS and SEC were responsible for data management; BPM analysed the data; JMa, LL and BPM wrote the paper; RWS, CRN, DR, MA, SLT, FJK and SEC critically reviewed the manuscript. All authors read and approved the final manuscript.

\section{Ethics approval and consent to participate}

Approval was by MUHAS ethical committee (MU/RP/AEC/NOL XI/33) and permission given by $\mathrm{MNH}$. Written informed consent was obtained from all participants. For individuals 18 years or above, while for minors, a parent/ guardian consented and signed the consent on behalf of the patient; adolescents provided assent. 


\section{Consent for publication}

Not applicable

\section{Competing interests}

The authors declare that they have no competing interests.

\section{Publisher's Note}

Springer Nature remains neutral with regard to jurisdictional claims in published maps and institutional affiliations.

\section{Author details}

${ }^{1}$ Muhimbili University of Health and Allied Sciences, Dar-es-Salaam, Tanzania. ${ }^{2}$ University of Oxford, Oxford, UK. ${ }^{3}$ Muhimbili National Hospital, Dar-es-Salaam, Tanzania. ${ }^{4}$ Dar-es-Salaam University College of Education, Dar-es-Salaam, Tanzania. ${ }^{5}$ University College London, London, UK. ${ }^{6}$ Centre for Geographic Medicine Research, Kenya Medical Research Institute, Kilifi, Kenya. ${ }^{7}$ National Institutes of Health, Bethesda, USA. ${ }^{8}$ London School of Hygiene \& Tropical Medicine, London, UK. ${ }^{9}$ National Institute for Medical Research Tanga Centre, Tanga, Tanzania.

Received: 11 March 2018 Accepted: 16 October 2018

Published online: 14 November 2018

\section{References}

1. Piel FB, Patil AP, Howes RE, Nyangiri OA, Gething PW, Dewi M, et al. Global epidemiology of sickle haemoglobin in neonates: a contemporary geostatistical model-based map and population estimates. Lancet. 2013;281: 142-51.

2. Weatherall D, Akinyanju O, Fucharoen S, Olivieri N, Musgrove P. Inherited disorders of hemoglobin. 2006.

3. Gaston M, Rosse WF. The cooperative study of sickle cell disease: review of study design and objectives. Am J Pediatr Hematol Oncol. 1982:4:197-201.

4. Telfer P, Coen P, Chakravorty S, Wilkey O, Evans J, Newell H, et al. Clinical outcomes in children with sickle cell disease living in England: a neonatal cohort in East London. Haematologica. 2007;92:905-12.

5. Gill FM, Sleeper LA, Weiner SJ, Brown AK, Bellevue R, Grover R, et al. Clinical events in the first decade in a cohort of infants with sickle cell disease. Cooperative Study of Sickle Cell Disease. Blood. 1995;86:776-83.

6. Lee A, Thomas P, Cupidore L, Serjeant B, Serjeant G. Improved survival in homozygous sickle cell disease: lessons from a cohort study. BMJ. 1995;311: $1600-2$

7. Diagne I, Diagne-Gueye ND, Signate-Sy H, Camara B, Lopez-Sall P, DiackMbaye A, et al. Management of children with sickle cell disease in Africa: experience in a cohort of children at the Royal Albert Hospital in Dakar. Med Trop (Mars). 2003;63:513-20.

8. Rahimy MC, Gangbo A, Ahouignan G, Adjou R, Deguenon C, Goussanou S, et al. Effect of a comprehensive clinical care program on disease course in severely ill children with sickle cell anemia in a sub-Saharan African setting. Blood. 2003:102:834-8.

9. Tshilolo L, Mukendi R, Girot R. Sickle cell anemia in the south of Zaire. Study of two series of 251 and 340 patients followed-up 1988-1992. Arch Pediatr. 1996; 3:104-11.

10. Dubert M, Elion J, Tolo A, Diallo DA, Diop S, Diagne I, et al. Degree of anemia, indirect markers of hemolysis, and vascular complications of sickle cell disease in Africa. Blood. 2017;130:2215-23.

11. Powars DR, Chan LS, Hiti A, Ramicone E, Johnson C. Outcome of sickle cell anemia: a 4-decade observational study of 1056 patients. Medicine (Baltimore). 2005:84: 363-76.

12. Piel FB, Steinberg MH, Rees DC. Sickle cell disease. N Engl J Med. 2017;377: 305

13. World Health Organisation. Sickle Cell Anaemia. Agenda item 11.4. 59th World Health Assembly, 27 May 2006. 2006.

14. World Health Organisation. The Brazzaville declaration on non-communicable diseases prevention and control in the WHO African region. 2011.

15. Tluway F, Makani J. Sickle cell disease in Africa: an overview of the integrated approach to health, research, education and advocacy in Tanzania, 2004-2016. Br J Haematol:2017:177:919-29.

16. Makani J, Cox SE, Soka D, Komba AN, Oruo J, Mwamtemi H, et al. Mortality in sickle cell anemia in africa: a prospective cohort study in Tanzania. PLoS One. 2011;6:e14699.
17. Makani J, Komba AN, Cox SE, Oruo J, Mwamtemi K, Kitundu J, et al. Malaria in patients with sickle cell anemia: burden, risk factors, and outcome at the outpatient clinic and during hospitalization. Blood. 2010;115:215-20.

18. Mmbando BP, Mgaya J, Cox SE, Mtatiro SN, Soka D, Rwezaula S, et al. Negative epistasis between sickle and foetal haemoglobin suggests a reduction in protection against malaria. PLoS One. 2015;10:e0125929.

19. Makani J, Mgaya J, Balandya E, Msami K, Soka D, Cox SE, et al. Bacteraemia in sickle cell anaemia is associated with low haemoglobin: a report of 890 admissions to a tertiary hospital in Tanzania. Br J Haematol. 2015;171:273-76.

20. Cox SE, Makani J, Fulford AJ, Komba AN, Soka D, Williams TN, et al. Nutritional status, hospitalization and mortality among patients with sickle cell anemia in Tanzania. Haematologica. 2011;96:948-53.

21. Cox SE, Soka D, Kirkham FJ, Newton CRJ, Prentice AM, Makani J, et al. Tricuspid regurgitant jet velocity and hospitalization in Tanzanian children with sickle cell anemia. Haematologica. 2014:99:e1-4.

22. Cox SE, Makani J, Newton CR, Prentice AM, Kirkham FJ. Hematological and genetic predictors of daytime hemoglobin saturation in Tanzanian children with and without sickle cell anemia. ISRN Hematol. 2013;2013:472909.

23. Makubi A, Mmbando BP, Novelli EM, Lwakatare J, Soka D, Marik H, et al. Rates and risk factors of hypertension in adolescents and adults with sickle cell anaemia in Tanzania: 10 years' experience. Br J Haematol. 2017:177:930-37.

24. Makani J, Menzel S, Nkya S, Cox SE, Drasar E, Soka D, et al. Genetics of fetal hemoglobin in Tanzanian and British patients with sickle cell anemia. Blood. 2011; 117:1390-2.

25. Mtatiro SN, Singh T, Rooks H, Mgaya J, Mariki H, Soka D, et al. Genome wide association study of fetal hemoglobin in sickle cell Anemia in Tanzania. PLoS One. 2014;9:e111464.

26. New. NBS. Geographical Information System (GIS). https://www.nbs.go.tz/ nbstz/index.php/english/geographical-information-system-gis. Accessed 30 Oct 2018.

27. Farber MD, Koshy M, Kinney TR, the Cooperative Study of Sickle Cell Disease. Cooperative study of sickle cell disease: Demographic and socioeconomic characteristics of patients and families with sickle cell disease. J Chronic Dis. 1985; 38:495-05.

28. King LGC, Bortolusso-Ali S, Cunningham-Myrie CA, Reid MEG. Impact of a comprehensive sickle cell center on early childhood mortality in a developing country: the Jamaican experience. J Pediatr. 2015;167:702-5.e1.

29. Ministry of Health and Social welfare Tanzania. In: Division of preventative health services, editor. National Strategy for Non-Communicable Diseases 2009-2015: Tanzania Food and Nutrition Centre; 2009.

30. Pegelow CH, Colangelo L, Steinberg M, Wright EC, Smith J, Phillips G, et al. Natural history of blood pressure in sickle cell disease: risks for stroke and death associated with relative hypertension in sickle cell anemia. Am J Med. 1997;102: $171-7$.

31. Campbell A, Minniti CP, Nouraie M, Arteta M, Rana S, Onyekwere O, et al. Prospective evaluation of haemoglobin oxygen saturation at rest and after exercise in paediatric sickle cell disease patients. Br J Haematol. 2009;147: 352-9.

32. Poillon WN, Kim BC, Castro O. Intracellular hemoglobin S polymerization and the clinical severity of sickle cell anemia. Blood. 1998;91:1777-83..

33. Makani J, Kirkham FJ, Komba A, Ajala-Agbo T, Otieno G, Fegan G, et al. Risk factors for high cerebral blood flow velocity and death in Kenyan children with sickle cell Anaemia: role of haemoglobin oxygen saturation and febrile illness. Br J Haematol. 2009;145:529-32.

34. Ojewunmi OO, Adeyemo TA, Osuntoki AA, Imaga NA, Oyetunji Al. Haemoglobin oxygen saturation, leucocyte count and lactate dehydrogenase are predictors of elevated cerebral blood flow velocity in Nigerian children with sickle cell anaemia. Paediatr Int Child Health. 2018;38: 34-39.

35. Setty BNY, Stuart MJ, Dampier C, Brodecki D, Allen JL. Hypoxaemia in sickle cell disease: biomarker modulation and relevance to pathophysiology. Lancet. 2003:362:1450-5.

36. Kirkham FJ, Hewes DKM, Prengler M, Wade A, Lane R, JPM E. Nocturnal hypoxaemia and central-nervous-system events in sickle-cell disease. Lancet. 2001;357:1656-9.

37. Cox SE, Makani J, Soka D, L'Esperence VS, Kija E, Dominguez-Salas P, et al. Haptoglobin, alpha-thalassaemia and glucose-6-phosphate dehydrogenase polymorphisms and risk of abnormal transcranial Doppler among patients with sickle cell anaemia in Tanzania. Br J Haematol. 2014;165:699-706.

38. Ballas SK, Gupta K, Adams-Graves P. Sickle cell pain: A critical reappraisal. Blood. 2012;120:3647-56. 
39. Maier-Redelsperger M, Noguchi CT, de Montalembert M, Rodgers GP,

Schechter AN, Gourbil A, et al. Variation in fetal hemoglobin parameters and predicted hemoglobin S polymerization in sickle cell children in the first two years of life: Parisian Prospective Study on Sickle Cell Disease. Blood. 1994;84: $3182-8$

40. Zhang D, Xu C, Manwani D, Frenette PS. Neutrophils, platelets, and inflammatory pathways at the nexus of sickle cell disease pathophysiology. Blood. 2016;127: 801-9.

41. Aliyu ZY, Gordeuk V, Sachdev V, Babadoko A, Mamman Al, Akpanpe P, et al. Prevalence and risk factors for pulmonary artery systolic hypertension among sickle cell disease patients in Nigeria. Am J Hematol. 2008:83:485-90.

42. Nagel RL, Rao SK, Dunda-Belkhodja O, Connolly MM, Fabry ME, Georges A, et al. The hematologic characteristics of sickle cell anemia bearing the Bantu haplotype: the relationship between $\mathrm{G}$ gamma and HbF level. Blood. 1987:69:1026-30.

43. Nagel RL, Ranney HM. Genetic epidemiology of structural mutations of the beta-globin gene. In: Seminars in hematology; 1990;342-59.

44. Makani J, Ofori-Acquah SF, Tluway F, Mulder N, Wonkam A. Sickle cell disease: tipping the balance of genomic research to catalyse discoveries in Africa. Lancet. 2017;389:2355-58.

45. Ribeil J-A, Hacein-Bey-Abina S, Payen E, Magnani A, Semeraro M, Magrin E, et al. Gene therapy in a patient with sickle cell disease. N Engl J Med. 2017; $376: 848-55$.

Ready to submit your research? Choose BMC and benefit from:

- fast, convenient online submission

- thorough peer review by experienced researchers in your field

- rapid publication on acceptance

- support for research data, including large and complex data types

- gold Open Access which fosters wider collaboration and increased citations

- maximum visibility for your research: over $100 \mathrm{M}$ website views per year

At BMC, research is always in progress.

Learn more biomedcentral.com/submissions 